\title{
Em busca de um modelo de leitura
}

\author{
Carla Viana Coscarelli \\ Universidade Federal de Minas Gerais
}

\section{Abstract}

In this paper we discuss some of the cognitive processes involved in reading, and the relationship among them. We also present a reading model, that may be called linear or serial, which is based on the theory of the modularity of the mind defended by Fodor (1983). Based on criticisms of this model, another is proposed, which, however, supports the parallel processing of the information. We propose as well a review of some concepts involved in the reading process, taking the relevance theory, proposed by Sperber and Wilson (1986/95), as a starting point. 


\section{INTRODUÇÃO}

$\mathrm{E}$

ste artigo aborda as operações mentais envolvidas na leitura, procurando discutir como acontecem algumas dessas operações. Sabe-se que a leitura envolve muitas operações cognitivas como o processamento lexical, o processamento sintático, construção da coerência (ou significado) local, construção da coerência temática e construção da coerência externa ou processamento integrativo (COSCARELLI, 1999).

Essas subdivisões são teóricas, ou seja, na prática ainda não é possível saber com certeza como elas acontecem. Alguns teóricos defendem que elas ocorrem em uma seqüência linear predeterminada e outros, que o processamento é paralelo, ou seja, que os domínios co-ocorrem. Essas e outras questões a respeito da leitura serão discutidas.

O modelo de leitura apresentado por COSCARELLI (1993) será tomado como base para novas reflexões para que se chegue a uma reestruturação e maior aprofundamento dele. Esse modelo tem como um dos seus principais pilares a teoria defendida por FODOR (1983) a respeito da modularidade da mente. Fodor defende a

"modularidade do sistema cognitivo, isto é, que este sistema seja constituído de módulos ou subpartes independentes que possuem várias características em comum e juntos formam uma unidade maior que é o sistema cognitivo" (COSCARELLI, 1993, p.7).

FODOR (1983) divide a mente humana em dois tipos principais de processamento: os sistemas de input (módulos) e o processador cognitivo, e propõe que a utilização da linguagem seja concebida como sendo uma interação entre eles. 
A função dos sistemas de input ou módulo lingüistico é receber os vários tipos de estímulos apresentados ao organismo e transformálos em representações mentais passíveis de serem processadas pelo processador cognitivo central. Esses sistemas têm traços que os caracterizam como modulares: são

\begin{abstract}
"módulos ou sistemas computacionais inatos, autônomos, involuntários e inconscientes que se caracterizam pela capacidade limitada de receber e armazenar informação, pela rapidez e pelo acesso restrito. Por acesso restrito entende-se que o usuário da linguagem não tem acesso às operações realizadas pelo módulo lingüístico, não podendo interferir em seu funcionamento. A função dos sistemas de input é alimentar o processador cognitivo central com informação ou estímulos do mundo exterior" (COSCARELLI, 1993, p.10).
\end{abstract}

O processador cognitivo, por sua vez, não apresenta características necessárias para ser considerado modular. As operações realizadas nele são voluntárias, não possuem as limitações dos módulos, têm velocidade variável e podem receber informações provenientes de outros domínios. Os diversos domínios de processamento envolvidos na leitura refletiriam essas características da teoria da modularidade de FODOR (1983), alguns apresentando traços que possibilitam a sua classificação como modulares e outros, não.

\title{
2. MODELO SERIADO DE LEITURA
}

De acordo com o modelo seriado, a leitura poderia ser dividida em domínios de processamento, ou seja, em conjuntos de operações cognitivas. Esses domínios podem ser divididos em dois grandes grupos: os domínios do módulo lingüístico - aqueles que lidam diretamente com o texto - e os domínios do processador cognitivo - aqueles que trabalhariam as informações já processadas pelo módulo lingüístico.

Entre os domínios do módulo lingüístico, estão o acesso lexical e o parsing sintático. O acesso lexical é o domínio no qual as 
informações fonológicas, fonéticas, morfológicas e sintáticas das palavras são ativadas. As informações resultantes do acesso lexical possibilitam a construção da estrutura sintática das frases, ou seja, o parsing sintático.

Esse modelo propõe também uma interface entre o módulo lingüístico e o processador cognitivo, na qual se dá o parsing semântico. Nesse domínio são construídas proposições, representações do conteúdo ou significado das sentenças que constituem unidades básicas do processamento cognitivo, a partir das estruturas sintáticas do texto, construídas no processamento sintático.

A construção de esquemas proposicionais e a integração de macroestruturas proposicionais do texto aos conhecimentos prévios do leitor parecem ser tarefas do processador cognitivo. Na construção de esquemas, o leitor relaciona proposições entre si, construindo com elas uma representação semântica do texto. Já no domínio em que ocorre a integração das macroestruturas proposicionais do texto aos conhecimentos prévios do leitor, as informações introduzidas pelo texto são relacionadas às informações sobre o mundo que o leitor tem na memória, modificando-as ou não.

Quanto à maneira como esses domínios articulam-se, o modelo seriado advoga que eles são ativados um após o outro durante a leitura (FODOR et al., 1974), seguindo uma seqüência linear e previamente determinada.

O produto das operações realizadas em um domínio serve de input para o domínio seguinte, formando uma cadeia de processamento de informação. De acordo com esse modelo, os domínios de processamento são:

1. Qualitativamente diferentes, ou seja, diferem-se em relação ao tipo de operação que realizam;

2. Independentes, uma vez que as operações de um domínio não sofrem interferência dos demais;

3. Ordenados no tempo, o que significa que as operações de um domínio começam quando as do domínio anterior terminam ou 
já estão avançadas, pois cada domínio depende de informações enviadas pelo domínio anterior.

A fundamentação empírica principal desse modelo é a variação do tempo de reação em diversas situações experimentais. Isso significa que o tempo que o leitor precisa para realizar as operações de cada domínio é diferente. E essa diferença é função, principalmente, das diferenças qualitativas existentes entre as operações realizadas pelos domínios. Experimentos mostram que o tempo normalmente necessário para se fazer o reconhecimento visual de uma palavra é sistematicamente menor que o tempo necessário para que o processamento sintático seja feito. O processamento sintático, por sua vez, requer menos tempo que o processamento semântico, e assim por diante.

\subsection{Críticas ao modelo seriado de leitura}

Os principais argumentos usados para colocar em dúvida esse modelo de processamento são a independência e a ordenação cronológica dos domínios, além do automatismo das operações realizadas por eles.

\section{a) Independência dos domínios}

Uma das questões que se pode usar para criticar o modelo seriado é a independência dos domínios. Eles são realmente independentes?

Essa é uma pergunta polêmica. Algum tempo e muito estudo serão necessários até que se encontre uma resposta fiável para ela. Existem dados confiáveis que comprovam tanto a dependência quanto a independência dos domínios. Um exemplo disso são os experimentos usando priming. ${ }^{1}$ Por um lado, muitos deles mostram que há influência de alguns domínios nas operações realizadas por outros, como costuma acontecer nos casos em que o contexto facilita (acelera) o reconhecimento de uma palavra. Se há facilitação, 
pressupõe-se que um domínio pode interferir nas operações realizadas por outros.

Muitos experimentos realizados para verificar a independência ou não dos domínios lidam com a ambigüidade tanto lexical quanto sintática. Alguns desses experimentos serão vistos a seguir a fim de que se possam analisar os problemas que essa questão pode suscitar, mostrando também que essa não é uma questão de resposta fácil, dada a dificuldade, sobretudo, da obtenção dos dados a serem estudados.

\section{Ambigüidade lexical}

No que diz respeito ao processamento lexical, existem evidências tanto a favor da autonomia quanto da dependência entre os domínios. De acordo com a visão autonomista, o leitor acessa automaticamente todos os sentidos da palavra (acesso múltiplo) e depois usa o contexto para selecionar o mais apropriado. $\mathrm{Na}$ visão interativa, em que há interdependência dos domínios, o contexto possibilita o acesso seletivo do sentido apropriado à situação, no caso de palavras ambíguas.

Usando a técnica de monitoração de fonemas, ${ }^{2}$ FOSS (1970) mostrou que palavras ambíguas gastam mais tempo para serem processadas mesmo quando elas são fortemente guiadas pelo contexto. Outros dados (SWINNEY, 1979) sugerem que, quando palavras ambíguas são ouvidas ou vistas, todos os significados delas são acessados inconsciente e imediatamente, mas o contexto é usado para rejeitar, muito rapidamente, todos os sentidos inadequados. Assim sendo, os significados menos freqüentes gastam mais tempo para serem acessados porque mais evidência é necessária para considerá-los como estando no contexto apropriado.

Tais estudos trazem evidências a favor do acesso múltiplo e, conseqüentemente, para a visão autonomista do processamento. Eles sugerem que o processamento lexical é autônomo, ou informacionalmente encapsulado, isto é, desempenha suas funções sem interfe- 
rência de outros domínios. Durante o processamento lexical, portanto, todos os sentidos de palavras ambíguas seriam produzidos e, somente num segundo momento, informações semânticas são usadas para selecionar o sentido apropriado.

Outros estudos mostram que fatores semânticos podem interferir no processamento lexical e que, em conseqüência disso, esses domínios de processamento não podem ser considerados autônomos. Alguns autores como MOSS \& MARSLEN-WILSON (1993) defendem que propriedades semânticas não são automaticamente acessadas quando ouvidas, mas podem ser afetadas pelo contexto anterior. Outros, como HOGABOAM \& PERFETTI (1975), mostram que o tempo gasto para acessar o significado de itens lexicais depende da freqüência de uso dos mesmos. As pessoas gastam mais tempo para detectar a ambigüidade quando a palavra ocorre na acepção mais freqüente, do que nos casos em que ela ocorre na acepção mais rara.

Os experimentos citados mostram que o processamento lexical depende de informações semânticas e, portanto, não pode ser visto como autônomo. Eles trazem indícios a favor do acesso seletivo em que o contexto vai favorecer a escolha de uma acepção, não ocorrendo então o acesso múltiplo automático.

As diferentes posições defendidas por esses estudos, entre outros, deixam bem claro que os dados e estudos não são suficientes para que se chegue a uma conclusão a respeito da autonomia ou não dos domínios de processamento. Uma das razões dessas discrepâncias é que os experimentos são feitos com métodos diferentes, materiais diferentes e sujeitos diferentes, sendo assim impossível, baseado somente nesses estudos, tomar alguma posição em relação à autonomia dos domínios.

\section{Ambigüidade sintática}

Outras evidências, tanto a favor quanto contra a independência dos domínios de processamento, podem ser tiradas dos experi- 
mentos relacionados com o processamento sintático. Na visão autonomista, há que se esperar até o final da sentença antes de o processamento semântico poder começar (na fala não é tão fácil saber onde é o fim da sentença). Os interacionistas, por sua vez, defendem que a construção de uma representação semântica e sua utilização podem começar imediatamente, de forma que a informação semântica possa guiar o processamento sintático.

Estudos trazem evidências a favor da autonomia do processamento sintático, mostrando que fatores semânticos não afetam o tempo de leitura. FERREIRA \& CLIFTON (1986), em experimentos medindo o movimento dos olhos e usando a técnica de leitura autocontrolada, concluíram que informações semânticas e pragmáticas não são usadas durante o processamento sintático inicial de uma sentença e, portanto, argumentam a favor da existência de um módulo de processamento sintático separado e independente do semântico. Esses resultados reforçam os obtidos por RAYNER et al. (1983) de que a plausibilidade de eventos do mundo real não influencia o processador lingüístico na sua escolha de uma análise sintática inicial de uma seqüência ambígua e endossam a idéia de que existem processadores distintos no mecanismo humano de compreensão de sentenças.

Outros estudos, por outro lado, mostram que um contexto semântico apropriado pode eliminar labirintos sintáticos (ALTMANN et al., 1994) e defendem que, nos casos de ambigüidade sintática ou labirintos, é possível que o processador faça a construção da representação sintática com base nas informações semânticas.

A partir desses e outros estudos é possível perceber que não há consenso em relação à autonomia dos módulos. Mais uma vez os diferentes métodos e materiais usados não permitem que se chegue a conclusão alguma a respeito dessa questão. Essa situação é reflexo do estágio ainda não muito maduro em que se encontram os estudos relacionados com essas questões em lingüística e na psicologia da linguagem.

No que diz respeito à epistemologia, é interessante que se tratem os domínios de processamento como sendo independentes 
para que esse estudo dos processos cognitivos envolvidos na leitura se viabilize. A divisão da leitura em domínios independentes, além de possuir suporte teórico e empírico, ainda que crivado de controvérsias, pode ser razoável num momento, dado que ainda não se tem conhecimento teórico e empírico suficiente para explicar com precisão as ligações que transformam essas partes independentes em um todo. Vista dessa maneira, a independência pode vir a ser considerada uma estratégia adotada para fins de estudo que não parece refletir fielmente a natureza do processo.

\section{b) Ordenação cronológica dos domínios: seriado x paralelo}

Uma outra questão passível de discussão é a ordenação cronológica linear dos domínios. Já existe na literatura informação suficiente para mostrar que essa idéia pode não ser sustentável, como é o caso do conexionismo, que defende a ativação positiva ou negativa das unidades envolvidas no processamento. Os efeitos de priming semântico também aqui servem como argumento para minar a idéia do processamento seriado. Outras situações em que é contrariada a idéia de que os domínios seguem uma ordem no tempo são os casos em que o conhecimento prévio do leitor e as suas expectativas em relação ao texto influenciam a leitura.

Um modelo de processamento em que os domínios funcionam independente e seriadamente tem dificuldades de explicar o processamento de textos, ${ }^{3}$ em que há uma relação direta entre o acesso lexical e a geração de esquemas sem necessariamente acionar o parsing sintático. O processamento de textos como esses implica saltos na seqüência de domínios de processamento, o que, a princípio, não seria possível nesse modelo.

Experimentos sobre o processamento sintático são muito usados para discutir a ordenação cronológica dos domínios. Durante a compreensão da linguagem, o leitor e o ouvinte sempre se encontram em uma situação em que têm de escolher entre várias análises sintáticas. O processamento de uma sentença, em especial aquelas com ambigüidade, pode ter várias soluções (MITCHELL, 1994): 
1. Uma só estrutura é construída;

2. Diferentes estruturas possíveis são construídas simultaneamente em paralelo;

3. A decisão é adiada até que informações suficientes estejam disponíveis.

Essas diferentes considerações a respeito do processamento sintático de sentenças ambíguas levaram à formação de várias correntes teóricas. A primeira reflete o pensamento dos que defendem um modelo seriado, a segunda, o dos defensores do processamento paralelo e a última, o dos adeptos dos modelos de comprometimento mínimo.

Os defensores do processamento seriado, como FRAZIER (1987), propõem que o processador sintático não considera essas ambigüidades e funciona da maneira autônoma e mais econômica possível, ou seja, adota imediatamente uma só estrutura: a sintaticamente mais simples. Se for construída uma estrutura incorreta em relação ao sentido do enunciado, uma reanálise dele deverá ser feita, aumentando conseqüentemente o tempo de processamento.

No processamento seriado, o sujeito lida com a ambigüidade estrutural, construindo uma representação única (total ou parcial) para a frase. Caso essa análise seja incompatível com o que vier depois na sentença, o sujeito anula a representação e constrói uma nova.

O processador de um modelo seriado rígido deve fazer suas decisões exatamente no momento em que os problemas aparecem. O processador não pode computar mais de uma estrutura e depois descartar as incorretas. Por outro lado, o processador de um modelo não-seriado pode voltar ao que já foi computado e adicionar mais detalhes ou mudá-los. Pode, portanto, processar uma sentença mesmo se alguma informação muito importante estiver faltando em um dado momento do processamento (FODOR, 1985). Ao contrário do que propõem os modelos seriados, nos modelos de processamento paralelo são construídas uma ou mais estruturas ao mesmo 
tempo e as análises que não forem compatíveis com a continuação da sentença serão eliminadas.

Outros autores divergem de FODOR (1985) e acreditam que é possível consertar o erro no modelo seriado. Quando o processador fica bloqueado, um procedimento de recuperação analisa globalmente o estado de configuração do próprio processador, adiciona informação nova sobre a sentença e apresenta a estrutura correta.

Estudos da psicolingüística sobre o processamento de sentenças, que tinham como base a gramática gerativa transformacional em sua primeira fase (CHOMSKY, 1957 e 1965), utilizavam modelos de processamento seriado. Algumas características desses modelos são:

- As operações de cada componente teriam de ser completadas antes de produzir seu output, que serve como input para o próximo nível de processamento no sistema;

- As operações são autônomas, ou seja, os processos dentro desses componentes são realizados sem referência a informações derivadas de outros componentes "mais altos" do sistema;

- A informação vem de níveis mais baixos do sistema e é seqüencialmente processada, nível por nível, até o output final ser produzido. O processamento é seqüencialmente organizado.

As principais características desse modelo são a autonomia sintática e o atraso da análise semântica das sentenças até uma representação da estrutura sintática profunda estar pronta. Isso significa que existiria um componente sintático autônomo que faria a computação da estrutura sintática profunda a qual agiria como input para o componente semântico. Regras de projeção operam nessa estrutura sintática profunda gerada, atribuindo interpretação semântica. Essa análise sintática não é, portanto, influenciada pelo significado.

TYLER (1981, p. 36) argumenta que nenhuma versão desse modelo apresenta uma explicação coerente do processamento de 
sentenças e que nenhum tipo de modelo seriado é compatível com os dados de processamento on-line. Segundo ela,

\begin{abstract}
"se a especificação sintática de cada palavra é suficiente para permitir a computação on-line tanto de uma estrutura sintática de superfície como de uma estrutura profunda, então parece implausível presumir que a descrição semântica de cada entrada lexical é insuficiente para permitir quaisquer processos combinatoriais on-line envolvendo semântica".
\end{abstract}

Uma outra crítica que se levanta em relação aos modelos seriados é a respeito do processamento das entradas lexicais. Uma incoerência que se pode perceber nesses modelos é que o output do processador sintático é passado ao processador semântico que, para efetuar seu tratamento, precisa ter acesso a certas informações fornecidas pelas representações lexicais que o processador sintático não utiliza. Postular a autonomia do tratamento sintático leva à postulação de um acesso disjunto dos processadores sintático e semântico às entradas lexicais, o que parece paradoxal quando se considera um encadeamento seriado. Um modelo seriado não permite uma volta ao que já foi processado, nem que o processador semântico tenha acesso direto às entradas lexicais. Somente o processador sintático tem acesso às entradas lexicais e, como o processador semântico precisa de informações a respeito dessa entrada, fica difícil explicar como o processamento semântico é feito.

Muitos experimentos trazem argumentos contra os modelos seriados (TYLER \& MARSLEN-WILSON, 1982). Esses experimentos sugerem que representações sintáticas e semânticas são computadas on-line ao mesmo tempo; isto é, que o ouvinte constrói uma representação do input em vários níveis à medida que ele o vai escutando. Desses experimentos - usando a técnica de speech shadowing, tarefas de monitoramento e tempo de reação, tarefa de continuação de sentenças e de identificação de palavras - costumase concluir que a interpretação, tanto sintática quanto semântica, começa muito cedo no processamento da sentença e que o processamento de input novo é determinado pelo contexto semântico que, 
por sua vez, influencia decisões sintáticas. Esses resultados sugerem que o processamento sintático não é autônomo e é afetado pela semântica.

Evidências desses experimentos mostram que o sujeito não segmenta o input em estruturas profundas baseadas na estrutura sintática, e só depois deriva uma interpretação semântica da unidade sintática. Ao contrário, análises sintáticas e semânticas desenvolvemse e se interagem desde o processamento da primeira palavra da sentença, isto é, operam paralelamente.

Existem duas possibilidades de processamento paralelo. Uma delas é que duas representações sejam computadas: uma para a organização sintática do input e a outra correspondendo à sua interpretação semântica. A segunda possibilidade é a computação de apenas uma representação de alto nível durante o processamento. $\mathrm{Na}$ verdade, é difícil distinguir as duas já que, na primeira possibilidade, os dois níveis de análise se realizariam concomitantemente e estariam em constante interação um com o outro.

\begin{abstract}
"Mas se esse é o caso, então não está claro qual seria a vantagem de computar duas representações distintas. Se o ouvinte puder contar simultaneamente com conhecimento tanto sintático quanto semântico para construir duas representações interdependentes, então essas duas representações dificilmente seriam distintas funcionalmente e a separação entre elas não serviria aparentemente a nenhum propósito para o sistema de processamento" (TYLER, 1981, p. 61).
\end{abstract}

Nesse caso, a distinção entre diferentes formas de conhecimento lingüístico não precisa ser mantida durante o processamento, pois elas devem cooperar para produzir uma única representação da sentença. Nenhuma fonte produz uma análise sozinha.

Mais uma vez o que se tem são argumentos tanto a favor quanto contra cada um desses dois tipos de processamento: seriado e paralelo. Portanto, tomar uma posição em relação a um ou outro não é tarefa fácil. Para isso é necessário que mais estudos e evidências estejam disponíveis. 


\section{c) Automatismo das operações}

Uma terceira razão para se questionar o modelo de leitura apresentado diz respeito ao automatismo das operações, isto é, à idéia de que as operações realizadas pelo módulo seriam sempre automáticas e, por isso, rápidas e sem o controle consciente do leitor. As operações realizadas pelo processador cognitivo, ao contrário, não seriam automáticas, portanto, seriam mais lentas e sofreriam controle consciente do leitor.

Há acesso limitado às representações que o sistema de input computa, os níveis mais baixos parecem ser completamente inacessíveis à consciência (FODOR, 1983). Ou seja, um usuário da língua não tem acesso igual a todos os níveis de representação dela. Resultados computacionais intermediários, ou seja, as representações fonética, fonológica, lexical e sintática intermediárias - produto dos sistemas perceptuais - parecem ser completamente inacessíveis à consciência e, portanto, independentes do que o sujeito supõe ou deseja.

Somente os outputs dos processadores perceptuais parecem ser de acesso livre para os processos cognitivos conscientes. Ao contrário das operações dos sistemas perceptuais, o processador cognitivo é um sistema computacional em grande parte voluntário e consciente, isto é, boa parte do que é feito nele depende do sujeito, que pode interferir em muitas de suas operações.

Existem fatores que fazem com que operações do módulo lingüístico não sejam automáticas. Isso acontece quando o leitor encontra alguma dificuldade na realização da tarefa. Pode-se perguntar se situações como essa fariam com que o acesso lexical, por exemplo, fosse uma operação temporariamente realizada pelo processador por se tornar mais consciente e mais lento. As operações a serem realizadas seriam as do domínio do acesso lexical, que é modular, mas a maneira de realizar essa tarefa seria do processador cognitivo? A tarefa de acesso lexical teria sua natureza alterada e se tornaria uma tarefa de solução de problemas e como tal passaria a ser responsabilidade do processador cognitivo? 
A automatização parece ser, portanto, uma questão de graus. Uma estrutura lingüística pode ser mais ou menos automática de acordo com seu uso. O maior uso de uma estrutura tem impacto positivo na sua automatização, ao passo que seu desuso tem impacto negativo. Com o uso constante, uma estrutura nova torna-se progressivamente mais automática.

Parece que algumas operações mentais envolvidas na análise e compreensão de textos são automáticas e, portanto, inconscientes, mas não foram sempre assim, tornaram-se com a prática assim, e qualquer problema como ambigüidade, palavras desconhecidas, estruturas sintáticas muito complexas, incoerência semântica, inadequação pragmática, falha na recepção ou transmissão do input, entre outros problemas, pode tornar consciente esse processamento. Nesses casos, o que deveria ser automático e mais inconsciente passa a ser desautomatizado e, portanto, mais consciente.

Tomando em consideração a teoria de FODOR (1983), segundo a qual uma das principais características das operações realizadas pelo módulo lingüístico é que elas seriam sempre muito automáticas, pode-se perguntar o que acontece quando um leitor tem problemas no acesso lexical. A teoria da modularidade trata o processamento lexical como uma operação não-controlada conscientemente pelo leitor e, como se sabe, a solução de problemas é uma das operações realizadas pelo processador cognitivo e, como tal, é controlada pelo leitor. Num caso como esses, o acesso lexical deixa de ser feito pelo processador lexical e passa a ser feito pelo processador cognitivo?

O automatismo das operações mentais é uma questão, como a da autonomia e o tipo de processamento, que coloca em dúvida o modelo seriado de leitura apresentado. Todas essas questões ainda requerem muito estudo até que se saiba como elas funcionam.

Não é intenção desse trabalho defender um tipo de modelo paralelo ou seriado e tomar uma posição rígida a respeito da autonomia ou não dos domínios. Essas são questões que requerem ainda muita pesquisa e o estágio atual dos estudos da psicolingüística não permite que se tome uma posição a respeito delas. Existem 
evidências a favor tanto de uma posição quanto da outra. O que se vai fazer é assumir algumas posições que parecem mais sustentáveis no momento e construir com elas um modelo de leitura.

Além dessas críticas ao modelo seriado, podem-se levantar outras críticas ao modelo de leitura apresentado por COSCARELLI (1993), por lidar com conceitos fixos, prontos, inflexíveis e por não tratar da leitura como um processo comunicativo e, conseqüentemente, não levar em consideração, fatores pragmáticos que interferem na compreensão de um texto. Essas questões serão discutidas na próxima seção.

\section{REVENDO ALGUNS CONCEITOS IMPORTANTES PARA UM MODELO DE LEITURA}

Para explicar a leitura como um processo comunicativo, talvez seja necessário perceber alguns conceitos, como conhecimento mútuo, conhecimento prévio e contexto, como sendo mais dinâmicos do que o postulado pelas teorias tradicionais. Também parece ser pertinente perceber a comunicação, conforme postula a Teoria da Relevância (SPERBER \& WILSON, 1986/95), não como um ato mecânico de codificação e decodificação de sinais, mas como um processo em que o autor procura manifestar suas intenções para o seu leitor, que, por sua vez, procura recuperar essas intenções construindo com as marcas textuais selecionadas pelo autor, e com as inferências que é capaz de fazer, um (ou mais) sentido(s).

O texto é fruto de um processo comunicativo, logo, a compreensão dele deve levar em conta: quem fala, o quê, para quem e com que objetivo (esses fatores dirigem a compreensão, limitam as possibilidades de inferências e minimizam as ambigüidades). Ou seja, a compreensão de um texto implica na aceitação prévia de que ele foi produzido por alguém que tem a intenção de comunicar algo, e que esse emissor selecionou para o seu texto elementos que vão permitir ao receptor recuperar essa informação fazendo as inferências necessárias para isso. 
Além de resultar da intenção de comunicação, o sentido construído pelo leitor é também uma questão de convenção. Todo enunciado contém instruções, ou seja, elementos indicadores de proposições, assim como dispositivos que indicam a força que o ato ilocucionário deve ter, através de aspectos como ordem vocabular, sintaxe, entoação, pontuação, modo de verbos performáticos, entre outros. Não se pode falar de significado sem forma, nem negar a influência dessa na construção daquela. Sendo assim, essas noções não podem ser separadas, ao contrário, uma sempre sofre influência e influencia a outra, enriquecendo a representação de ambas.

O texto ou material lingüístico possui muitas marcas ou instruções procedimentais e conceituais, que resultam em restrições na construção do significado, ou seja, que dirigem a compreensão, limitando as possibilidades de sentido que o leitor pode construir a partir dele. Essas marcas lingüísticas codificam "restrições na gama de interpretações possíveis, e podem ser consideradas como uma gramaticalização da interpretação" (ESCANDELL-VIDAL, 1998, p. 57). Isso faz com que o texto tenha um número finito e limitado de possibi-lidades de interpretação e, conseqüentemente, restringe também a produção de inferências.

Durante a leitura, o leitor precisa identificar as relações existentes entre a sentença que está lendo e as anteriores a ela. A identificação da relação desejada pelo autor depende da forma como o leitor usa as instruções que o autor forneceu e/ou como infere a relação pretendida por ele.

O leitor não identificar a relação desejada pelo autor ou próxima dela pode ser conseqüência dos seus objetivos na leitura do texto, da ineficiência do leitor, ou da insuficiência de marcas ou instruções no texto, ou seja, o leitor construir a estrutura desejada depende das instruções que o autor colocou no texto e também do que o leitor faz com aquelas instruções.

Uma inevitável pergunta se levanta a partir dessas considerações: quais são os mecanismos lingüísticos que dirigem a compreensão de um texto? No caso das inferências, quais seriam os 
mecanismos lingüísticos que estimulariam a produção delas e que mecanismos limitariam e/ou dirigiriam essa produção? Talvez a resposta seja: todos. Várias teorias buscam evidenciar esses mecanismos lingüísticos e explicar o funcionamento deles. Mas só a forma não é capaz de explicar e restringir todas as possibilidades de leitura. Na compreensão de um texto, o leitor não conta só com informações lingüísticas, mas também com o contexto situacional e cultural (HALLIDAY \& HASAN, 1976), ou melhor, ao material lingüístico somam-se informações extralingüísticas. O total das informações conscientes e potencialmente conscientes de que dispõe um determinado indivíduo pode ser chamado de conhecimento prévio. Essa noção precisa ser dinâmica e variável, pois é constantemente modificada de acordo com as alterações nos contextos lingüístico, situacional e cultural.

Além da noção de conhecimento prévio, outra carece de revisão: a de conhecimento mútuo ou partilhado. Devem-se entender esses conceitos como sendo pontos semelhantes no conhecimento dos interlocutores. Dessa forma, não se pressupõe que autor e leitor têm o mesmo conhecimento, mas que, por causa das diferenças de habilidades cognitivas de ambos, eles nunca compartilham totalmente seus conhecimentos. Dizer que, na comunicação, os interlocutores levam em consideração seu conhecimento partilhado não implica, então, que eles façam as mesmas conjecturas, mas que podem fazer isso.

O dinamismo que está sendo incorporado ao conceito de conhecimento prévio e que faz dele um elemento em constante reestruturação parece mais pertinente que a noção estática adotada pelas teorias tradicionais. Esta, ao contrário do que está sendo proposto, é normalmente vista como um composto de informações prontas, estocadas em algum lugar, à espera do momento em que serão usadas. Nessa proposta, as informações armazenadas na memória são constantemente reformuladas, ativadas e desativadas, ou seja, sofrem alterações em função tanto das modificações provocadas pelas informações lingüísticas e extralingüísticas como também em função dos objetivos do leitor. 
O mesmo acontece com o conceito de contexto, que não será entendido como algo fixo e pronto. Propõe-se a noção de contexto como sendo variável, constituído de informações que se modificam continuamente ao longo da situação comunicativa.

\section{MODELO DE LEITURA REESTRUTURADO}

Apresentadas críticas ao modelo de leitura seriado e proposta uma nova visão de conceitos básicos para uma teoria da compreensão, busca-se agora construir um modelo em que todas as partes se relacionem, mas sem perder sua autonomia; em que não haja necessariamente uma arquitetura linear, ou seja, em que o processamento não seja inerentemente ordenado; que lide com conceitos mais flexíveis e dinâmicos.

O modelo reestruturado, que está sendo proposto, parece ser um passo em direção à realização dessa tarefa. Esse modelo, que não deve ser tão cheio de restrições quanto o modelo seriado nem tão livre delas, é composto de cinco domínios: o processamento lexical, o processamento sintático, a construção da coerência (ou significado) local, a construção da coerência temática e a construção da coerência externa ou processamento integrativo. Esses domínios têm muito em comum com os domínios apresentados em COSCARELLI (1993), mas trazem algumas modificações, sobretudo no que se refere à maneira como eles se interrelacionam. Ou seja, o modelo apresentado em COSCARELLI (1993) era seriado, isto é, postulava-se que os domínios de processamento eram ativados um após o outro durante a leitura (FODOR et al., 1974). O modelo reestruturado que será proposto defende que não seja preciso passar por todos os domínios de processamento em uma ordem previamente estabelecida. Pode ser que todos, ou alguns deles, ocorram paralelamente. Além disso, no modelo reestruturado, as operações dos domínios são "regidas" pela pragmática, ou seja, por informações extratextuais que vão, juntamente com as informações lingüísticas, orientar o leitor na construção do sentido do texto. 


\subsection{Sobre o funcionamento do modelo reestruturado}

De acordo com esse modelo, alguns domínios têm como input estímulos externos e outros lidam com estímulos internos. O processamento lexical e o processamento sintático lidam diretamente com o estímulo externo, isto é, operam com elementos do texto. A construção da coerência (ou significado) local, construção da coerência temática e construção da coerência externa ou processamento integrativo lidam com estímulos internos. Estímulos internos são informações advindas dos outros domínios de processamento (como por exemplo, a macroestrutura proposicional construída pelo leitor), dos elementos ativados naquele momento, ou informações, advindas do estímulo externo, recém-processadas por algum domínio que lida diretamente com esse tipo de estímulo.

Como existe uma relação de interdependência entre os domínios, aqueles que operam sobre o estímulo externo o fazem contando também com informações advindas de outros domínios. Isso é constatado em experimentos que utilizam o priming e em outras situações nas quais se percebe a influência do conhecimento prévio na leitura, como nos casos em que o leitor faz inferências.

A interdependência entre os domínios é responsável pela desestabilização e estabilização do sistema. Ou seja, todos os domínios são acionados paralelamente e as alterações feitas na informação por um domínio obrigam todos os outros domínios a se adaptarem àquela nova arquitetura (representação) da informação.

Os domínios de processamento visam à estabilização, ou seja, procuram maximizar a coerência entre o estímulo recebido e o estado prévio do leitor. Há uma constante comunicação entre os diversos domínios a fim de que se construa a coerência da informação que está sendo processada ou para que uma coerência já construída se mantenha. A cada modificação em qualquer parte do sistema, as outras partes precisam ser ativadas para checar se alguma outra operação precisa ser feita para que esse objetivo de manter ou chegar à coerência seja atingido. 
Para que essa constante busca da estabilização feita pelo sistema seja possível, defende-se aqui que cada componente do processo traria restrições para a formação de uma representação mental coerente do texto. Da mesma forma que parecem existir restrições para a boa formação de sentenças, é bastante provável que haja restrições para a boa formação de palavras, proposições, esquemas e, finalmente, de uma representação mental do texto. O reconhecimento de uma palavra, por exemplo, constitui uma restrição sobre as estruturas sintáticas que ela pode acionar. O contrário também acontece, a identificação ou escolha, primeiramente, da estrutura sintática restringe a seleção lexical das palavras subseqüentes.

Isso significa que vários fatores estão envolvidos na construção da coerência. A completa estabilização do sistema é praticamente impossível já que ele está sempre sendo estimulado por um contexto dinâmico, em constante modificação. Mas a busca dessa estabilização é viabilizada pelo trabalho do autor na seleção de marcas lingüísticas tais que serão usadas pelo leitor para reconstruir uma intenção comunicativa próxima da pretendida por aquele. Além disso, outros elementos, como o contexto situacional e os conhecimentos compartilhados pelos interlocutores, servem de suporte para a reconstrução dessas intenções, ou seja, para que uma representação do texto seja construída e fazendo com que o sistema mental aproxime-se de uma estabilização, o leitor conta com informações não só lingüísticas, mas também culturais e situacionais.

A ativação dos domínios é coordenada e as operações realizadas em um domínio normalmente requerem a ativação de outros domínios, para que eles se ajustem às operações realizadas pelo outro durante o processamento da informação, a fim de manter a coerência do processamento da mesma. No entanto, cada domínio realiza operações específicas e, portanto, eles são qualitativamente diferentes. Essa diferença qualitativa entre os domínios é responsável por uma diferença quantitativa nas ativações dos domínios. Isso quer dizer que o grau de ativação de cada domínio em função de operações realizadas em algum deles varia de acordo com o nível 
de relacionamento dessas operações. Existem operações mais e menos dependentes e, provavelmente, operações completamente independentes. Quanto maior a interdependência entre as operações, mais os domínios que realizam essas operações serão ativados, por conseguinte, domínios que realizam operações pouco relacionadas com a operação em curso serão pouco ativados. Só não haverá ativação de um domínio nos casos de total independência entre a operação em andamento e esse determinado domínio.

Uma proposição, por exemplo, não é construída isoladamente; está sempre ligada a um conjunto de proposições interrelacionadas. As proposições podem ser diretamente derivadas do texto ou do conhecimento prévio do leitor e são interligadas de diferentes maneiras: sintaticamente, semanticamente, via estrutura do discurso e através do seu conhecimento geral de mundo. Essas ligações entre as proposições refletem a força com a qual elas foram conectadas no texto, assim como refletem as conexões preexistentes na memória do leitor, ou seja, uma proposição construída aciona outras fortemente ligadas a ela e desativa aquelas não-relacionadas (ERICSSON \& KINTSCH, 1995).

Em suma, o modelo revisto continua tendo as variações em função das diferenças qualitativas dos domínios, mas como a ativação dos domínios não é necessariamente seriada, e sim provavelmente paralela (ou simultânea), será possível explicar algumas questões que o primeiro modelo não era capaz de explicar. Pode-se citar, como exemplo, os casos em que há a influência da informação contextual nas decisões do processador sintático ou os casos de palavras polissêmicas em que é preciso usar o contexto para que se possa selecionar o significado adequado. Propriedades semânticas de uma palavra podem ser reguladas pelo contexto que a antecede. Isso indica que existe uma forte relação entre o contexto e o significado das palavras e sentenças.

Um progresso do modelo reestruturado em relação ao seriado é que o primeiro justifica a dúvida de qual determina qual: se é a sintaxe que determina a semântica ou vice-versa. Essa dúvida só tem sentido 
no modelo seriado já que no modelo reestruturado os domínios se interrelacionam e, com isso, nenhum domínio determina diretamente a ação do outro. A ativação dos domínios vai depender da proximidade das relações exigidas pela informação a ser processada.

As operações realizadas pelos domínios de processamento que lidam diretamente com estímulos externos são normalmente realizadas num espaço de tempo mais curto que as operações dos outros domínios. O modelo reestruturado postula a existência de um continuum no que diz respeito ao tempo necessário para que cada domínio realize suas tarefas. À medida que o processamento vai sendo feito pelos domínios, "resultados parciais" desses processamentos vão sendo "liberados" para que outros domínios lancem mão deles no intuito de completar a sua tarefa. Esse processamento não tem fim, já que os domínios estão sempre recebendo estímulo externo e/ou interno para serem processados. O que se pode saber é o grau de ativação e de conexão entre as informações que estão sendo processadas pelos domínios em um determinado momento.

Quando um sujeito termina de ler um texto, por exemplo, deve haver uma maior estabilização das suas representações mentais em comparação com o estado delas quando a leitura ainda estava sendo feita. Mas, na verdade, essas representações não se estabilizam completamente nunca. Toda vez que o sujeito pensar no que leu ou fizer alguma associação daquilo com alguma outra coisa, ou seja, toda vez que aqueles elementos da representação forem acionados, haverá modificação da estrutura construída para o texto. Por outro lado, quanto menos relacionadas forem as informações, menor será seu grau de probabilidade de ativação.

O grau de ativação potencial explica o funcionamento da memória. Memória é a quantidade de ativação real ou potencial. $\mathrm{O}$ que se entendia como memória de trabalho, isto é, o armazenamento temporário de informação mantido acessível por um curto período sem ensaio ou reativação, é entendido neste modelo como os elementos em processamento. Ao que tudo indica, memória é também uma questão de grau. Os elementos podem estar ativados 
em maior ou menor grau, formando uma escala de ativação em que existem os elementos mais ativados, os menos ativados, e os mais ou menos potencialmente ativáveis.

Quando um determinado conceito é acionado, por exemplo, hospital, elementos ligados a ele são também ativados ou ficam em estado latente de ativação podendo ou não ser ativados, dependendo do "rumo" que o assunto tomar. Isso acontece porque algumas ligações são mais freqüentes que outras. Sempre que se fala em hospital existe uma grande freqüência de conceitos que costumam aparecer também, como médico, doença, cheiro de éter, etc. Outros conceitos raramente aparecem ligados a eles, como receita de crochê, por isso não costumam ser acionados durante o processamento de elementos como hospital. Essas ligações entre os elementos diferem de pessoa para pessoa já que a experiência de cada uma em relação ao significado das palavras é diferente. Um médico, por exemplo, ao receber a palavra hospital como estímulo, terá elementos acionados diferentes daqueles acionados por um engenheiro especializado em construir hospitais, que, por sua vez, acionará elementos diferentes dos acionados em um paciente do hospital, e assim por diante.

Esse modelo explica mais facilmente as inferências, que são uma conseqüência natural do funcionamento desse sistema. Um estímulo, seja ele interno ou externo, aciona várias ligações em graus diferentes. Na leitura, as entidades, estados, eventos e relações acionados que não foram explicitamente mencionados nos textos, mas que são ativados, são inferências. As inferências são resultado da ativação das ligações mais freqüentes ou mais recentemente ativadas entre os elementos.

Vê-se, portanto, que parece haver uma gama variada de ligações entre os elementos processados que pode ir das ligações inexistentes às sempre muito freqüentes, passando pelas raras, recentemente freqüentes, e freqüentes. Um exemplo de ligações provavelmente inexistentes seria o caso da relação entre pêra e esmeril. ${ }^{4}$ Para a maioria das pessoas essa ligação é muito indireta ou inexistente. 
No outro extremo, estaria a relação entre futebol e gol, por exemplo. Para todo mundo que conhece esse jogo há uma ligação muito direta entre esses dois elementos. Para quem mora no Brasil e é do sexo masculino, então, essa é uma ligação sempre muito ativada.

As relações raras são as existentes, mas pouco freqüentes. Um jovem que escuta, por exemplo, a sentença isso não é legal, muito provavelmente vai pensar que o falante está querendo dizer isso não está bom, ou qualquer coisa semelhante. Ele não pensará em legal significando dentro da lei, porque a ocorrência dessa acepção é muito rara para ele. O contrário talvez não pudesse ser dito em relação a um advogado. Mesmo tendo a segunda acepção da palavra legal mais freqüentemente acionada em seu ambiente de trabalho, o uso de legal como gíria é também muito freqüente no uso coloquial da língua portuguesa. Logo, para o advogado é provável que as duas acepções sejam freqüentes e, conseqüentemente, o que vai fazer com que uma ou outra fique mais ativada é o contexto lingüístico e pragmático em que ela vai ocorrer. Se esse advogado estiver conversando com sua filha adolescente, a probabilidade de legal aparecer como gíria é muito maior do que como termo usado no Direito. Assim sendo, a acepção de legal como gíria está potencialmente mais ativada.

Ativações recentemente ativadas são aquelas normalmente não muito freqüentes, mas que têm sido ativadas com mais freqüência recentemente.

Em suma, pode-se dizer que existem ativações mais e menos diretas, e mais e menos freqüentes entre os elementos que estão sendo processados. Tem-se, portanto, uma ampla gama de graus de ativação que vai determinar a produção de inferências. O texto bem como o contexto têm papel importante na seleção dos elementos que serão ou não ativados.

O critério contextual ou pragmático pode suplantar o critério semântico na organização de esquemas e, conseqüentemente, influenciar na potencialidade de ativação. Por exemplo, nas notícias de jornal, há vários critérios para definir a "estrutura de relevância" 
desse tipo de discurso e, além da importância semântica, tem-se também a relevância pragmática, como por exemplo, o interesse dos leitores e as implicações de fatores como a recência do fato noticiado. Isso significa que algumas vezes as informações sobre eventos recentes podem ser privilegiadas em relação a informações semanticamente mais relevantes e, por isso, serem escolhidas para serem manchetes ou lead da notícia (VAN DIJK, 1997), fazendo com que os leitores gerem expectativas, ativando informações que podem não ser as mais necessárias à compreensão do texto. Isso não representa, necessariamente, um problema para o leitor, pois este desenvolve e modifica as representações construídas durante a leitura em função do contexto, ou melhor, dos seus modelos desse contexto. Essas operações realizadas durante o processamento têm uma natureza estratégica. Elas podem falhar, mas são rápidas, são dependentes do contexto, são orientadas pelos objetivos do leitor, podem operar em vários níveis ao mesmo tempo e possibilitam a rápida produção de inferências na presença de dados incompletos (VAN DIJK, 1997), sendo, portanto, de suma importância na compreensão.

\section{CONSIDERAÇÕES FINAIS}

Neste artigo procurou-se estabelecer um contraste entre o modelo seriado de leitura e o modelo paralelo - reestruturado apresentando-se críticas àquele que motivaram a construção deste. Ressalta-se que esses modelos são abstrações teóricas construídas na busca de uma explicação plausível do processamento cognitivo da leitura que, por sua vez, ainda só pode ser estudada através de medidas indiretas e, portanto, nem sempre muito confiáveis.

O modelo reestruturado de leitura apresenta uma evolução teórica em relação ao primeiro, mas ainda há muito o que ser discutido e repensado em relação a ele. Fica, então o convite e a esperança de que esse trabalho sirva de estímulo para quem quiser se enveredar pelos caminhos ainda obscuros e fascinantes dos estudos lingüísticos e da cognição. 


\section{NOTAS}

${ }^{1}$ Priming é uma "metodologia para se investigar o que acontece quando uma palavra precede outra. A primeira palavra, ou prime, deve acelerar o reconhecimento da segunda palavra, ou alvo. Nesse caso falamos de facilitação. Em alguns casos, no entanto, o prime pode fazer com que a identificação do alvo seja mais demorada. Nesses casos falamos de inibição. Na maioria das vezes priming semântico é usado para se referir à facilitação semântica." (HARLEY, 1995, p. 71).

${ }^{2}$ Nessa tarefa, os sujeitos têm de monitorar a fala em busca de um som particular ou fonema e pressionar um botão quando eles o detectarem.

3 Podem-se citar como exemplos os textos "A Pesca" de Affonso Romano de Sant'Anna e "Circuito Fechado" de Ricardo Ramos.

${ }^{4}$ Os exemplos dados aqui são de processamento lexical, mas podem ser ampliados para relações sintáticas e semânticas mais complexas.

\section{REFERÊNCIAS BIBLIOGRÁFICAS}

ALTMANN, Gerry T. M.; GARNHAM, Alan; HENSTRA, Judith-Ann. Effects of syntax in human sentence parsing: evidence against a structure-based proposal mechanism. Jounal of Experimental Psychology: Learning, Memory and Cognition. v.20, n.1, p.209-216, 1994.

CHOMSKY, N. Aspects of the theory of syntax. Cambridge, Mass.: The MIT Press, 1965.

CHOMSKY, N. Syntactic structures. Janua Linguarum, 4. The Hague: Mouton, 1957.

COSCARELLI, C. V. Leitura em ambiente multimídia e a produção de inferências. 1999. Tese (Doutorado em Estudos Lingüísticos) - Faculdade de Letras, Universidade Federal de Minas Gerais, Belo Horizonte.

COSCARELLI, Carla V. Leitura de elementos coesivos nominais na $1^{\underline{a}}$ série. 1993. Dissertação (Mestrado em Estudos Lingüísticos) - Faculdade de Letras, Universidade Federal de Minas Gerais, Belo Horizonte.

ERICSSON, K. Anders; KINTSCH, Walter. Long-term working memory. Psychological, 1995. 
ESCANDELL-VIDAL, V. Metapropositions as metarepresentations. II RT Workshop Book of Review, v.102, n.2, p.211-245, 1995. Abstracts, p.57-62, 1998.

FERREIRA, F.; CLIFTON, C. The independence of syntactic processing. Journal of Memory and Language. n. 25, p. 348-368, 1986.

FODOR, Janet D. Deterministic parsing and subjacency. Language and Cognitive Processes, v.1, n. 1, p.3-42, 1985.

FODOR, Jerry A. The modularity of mind. Cambridge, MA: MIT, 1983.

FODOR, Jerry; BEVER, T.; GARRETT, M. The Psychology of language: a introduction to Psycholinguistics and Generative Grammar. New York: McGrawHill, 1974.

FOSS, D. J. Some effects of ambiguity upon sentence comprehension. Journal of Verbal Learning and Verbal Behavior, n. 9, p.699-706, 1970.

FRAZIER, Lyn. Sentence processing: a tutorial review. In: ColtheART (Ed.), 1987.

HALLIDAY, M. A. K.; HASAN, R. Cohesion in English. London: Longman, 1976.

HARLEY, Trevor A. The psychology of language: from data to theory. UK, Erlbaum (UK): Taylor, Francis, 1995.

HOGABOAM, T. W.; PERFETTI, C. A. Lexical ambiguity and sentence comprehension: the common sense effect. Journal of Verbal Learning and Verbal Behavior, n.14, p. 265-275, 1975.

MITCHELL, Don C. Sentence parsing. In: GERNSBACHER, M A. Handbook of Psycholinguistics. San Diego: Academic Press, p.375-409, 1994.

MOSS, H. E.; MARSEN-WILSON, W. D. Access to word meaning during spoken language comprehension: effects of sentential semantic context. Journal of Experimental Psychology: Learning, Memory and Cognition, n.19, p.1254-1276, 1993.

RAYNER, Keith; CARLSON, Marcia; FRAZIER, Lyn. The interaction of syntax and semantics during sentence processing: eye movement in the analysis of semantically biased sentences. Journal of Verbal Learning and Verbal Behavior, n.22, p.358-374, 1983.

SPERBER, Dan; WILSON, Deirdre. Relevance: comunication and cognition. Oxford, Cambridge: Blackwell, 1986/1995.

SWINNEY, D. A. Lexical access during sentence comprehension: (re)consideration of context effects. Journal of verbal learning and verbal behaviour, n.18, p.645659, 1979. 
TYLER, Lorraine K.; MARSLEN-WILSON, W. D. Processing utterances in discourse contexts: on-line resolution of anaphors. Journal of Semantics, v.1, n. 4, p. 297314, 1982

TYLER, Lorraine K. Serial and interactive-parallel theories of sentence processing. Theoretical Linguistics, Berlin, v. 8, n.1-3, p. 29-65, 1981

VAN DIJK, T. A. Cognitive context models and discourse. Disponível em <http:/www.let.uva.nl/ teun>. 1997. 